\title{
TRADIÇÕES DISCURSIVAS NO PORTUGUÊS DO BRASIL: AS ORIGENS DO EDITORIAL JORNALÍSTICO NA IMPRENSA PAULISTANA
}

\author{
Vicente Luís de Castro Pereira*
}

\begin{abstract}
Resumo: Dentre as questões que atualmente se colocam no primeiro plano das discussões sobre o ensino da língua portuguesa no Brasil, destaca-se a preocupação com os diferentes gêneros discursivos e com o trabalho a ser realizado, no ambiente escolar, sob essa perspectiva. Aliada ao estudo dos gêneros discursivos, uma outra abordagem, bastante recente no campo dos estudos lingüísticos brasileiros, vem contribuir para a compreensão do assunto, situandose em torno das chamadas tradições discursivas, um tema de estudo de atuais pesquisas realizadas por lingüistas alemães. Neste trabalho, busca-se, com base no conceito de tradições discursivas, restabelecer o percurso histórico de constituição do editorial. Toma-se, como objeto de estudo, um periódico do século XIX intitulado O Farol Paulistano, o primeiro jornal impresso da cidade de São Paulo.
\end{abstract}

Palavras-chave: análise diacrônica do discurso; tradições discursivas; gêneros discursivos; editorial; periódicos brasileiros do século XIX; O Farol Paulistano.

[...] um número considerável das atuais questões centrais da teoria da linguagem só serão resolvidas se resistirem, de certa forma, a uma revisão a partir da perspectiva histórica.

Johannes Kabatek (2004)

\section{Todos os gêneros são históricos e têm origem em práticas sociais}

.L. A. Marcuschi (2000: 104), apud Gomes (2005: 89)

Graduação em Letras - FFLCH/ Universidade de São Paulo 


\section{Introdução}

Dentre as questões que atualmente se colocam no primeiro plano das discussões sobre o ensino da língua portuguesa no Brasil, destaca-se a preocupação com os diferentes gêneros discursivos e com o trabalho a ser realizado, no ambiente escolar, sob essa perspectiva. Aliada ao estudo dos gêneros discursivos que exercem coerções sobre os textos a serem produzidos, uma outra abordagem, bastante recente no campo dos estudos lingüísticos brasileiros, vem contribuir para a compreensão do assunto, situando-se em torno da teoria das chamadas tradições discursivas, um tema que vem sendo objeto de estudo de atuais pesquisas realizadas por lingüistas alemães. Tal abordagem visa o estudo histórico dos gêneros discursivos e o mapeamento de suas origens, a partir da identificação de esquemas textuais e modelos de realização discursiva que guiam a produção dos discursos individuais. Do ponto de vista do ensino, um enfoque histórico sobre os diversos gêneros discursivos existentes permite o desenvolvimento de projetos interdisciplinares que valorizem a preservação do passado cultural, na medida em que textos e documentos antigos constituem as fontes que conservam a memória de um período afastado temporalmente, permitindo a realização de reflexões e revisões críticas dos fatos com os olhos do presente.

Este artigo tem como objetivo central reconstituir o percurso histórico do gênero discursivo editorial, por meio da análise das cartas do redator do periódico $O$ Farol Paulistano - primeiro jornal impresso da cidade de São Paulo, cujos números circularam entre os anos de 1827 e 1831 -, verificando de que modo a configuração inicial do modelo discursivo em estudo foi mantida ou alterada no decorrer do tempo, até chegar à forma como se apresenta nos dias atuais. Ao realizar o mapeamento das origens do editorial jornalístico na imprensa paulistana, levando em consideração aspectos relativos à contextualização histórico-ideológica, o trabalho permite o estabelecimento de comparações com a configuração geral assumida pelo gênero discursivo em questão nos jornais da atualidade. A pesquisa toma, como eixo teórico das análises, o conceito de tradições discursivas, fundamentando-se nos recentes trabalhos desenvolvidos por Kabatek (2001, 2003, 2004), Oesterreicher (1996, 2001, 2002) e Schmidt-Riese (2002), sob a perspectiva epistemológica da Análise Diacrônica do Discurso - linha de estudos que vem alcançando resultados produtivos no âmbito das pesquisas realizadas, sobretudo, na área da Filologia Românica alemã, na tentativa de aliar o conhecimento lingüístico à reflexão histórica.

Quanto aos procedimentos metodológicos utilizados, realizou-se, em uma primeira etapa, um trabalho de leitura e delimitação dos elementos gerais relacionados ao gênero discursivo em estudo, mediante consultas a rolos de microfilmes pertencentes à coleção de periódicos brasileiros do século XIX, do Instituto de Estudos Brasileiros (IEB-USP). Concluída esta parte de verificação das origens do gênero editorial nas cartas do redator d'O Farol Paulistano, bem como finalizada a reflexão sobre a bibliografia teórica básica, iniciou-se o trabalho de reconstituição do percurso histórico do gênero textual. Identificando as relações mantidas entre os textos das cartas do redator - levando em conta 
suas posturas ideológicas, comentários e opiniões -, assim como os aspectos relativos ao contexto histórico no qual se inserem, foi possível identificar, do ponto de vista da configuração textual, os traços caracterizadores originais apresentados pelo gênero e sua adequação à linha de pensamento e à proposta editorial seguidas pelo jornal. Foram igualmente verificadas as funções que o gênero jornalístico analisado desempenhava inicialmente na história do jornalismo paulistano e as alterações sofridas no modo de expor e argumentar, no modo de estruturação do texto, no reflexo das influências externas ou contextuais recebidas, até chegar à configuração que pode ser observada pelos leitores atuais, nos jornais contemporâneos.

Em síntese, o texto que segue abaixo é resultado das etapas de trabalho acima descritas e procura contribuir para a reconstrução do trajeto histórico percorrido pelo gênero jornalístico editorial, no momento de formação da imprensa paulistana. Dessa forma, partindo de um trabalho prático de observação e análise do material selecionado, delimitando os elementos gerais caracterizadores do gênero discursivo em questão, levando em consideração a adequação dos textos ao contexto de época e à postura ideológica assumida pelo primeiro periódico paulistano impresso, tornou-se possível reconstituir as características gerais e os traços lingüístico-discursivos que constituíam os primitivos editoriais jornalísticos, tal como se apresenta a seguir.

\section{Pressupostos teóricos: tradições discursivas e historicidade}

Dado o fato de serem ainda muito recentes, sobretudo no universo científico brasileiro, as pesquisas nas áreas de Pragmática Histórica e Análise Diacrônica do Discurso $^{1}$, fazem-se necessárias algumas linhas de cunho teórico para situar alguns conceitos imprescindíveis à adequada compreensão da análise realizada na segunda seção deste texto. Em primeiro lugar, considera-se que toda produção textual requer o conhecimento, por parte do indivíduo que fala ou escreve, de modelos de realizações discursivas anteriormente produzidos pela sociedade, denominados tradições discursivas (TDs). O estudo desses modelos discursivos gerais, que guiam o discurso individual, parte da convergência entre os estudos da Pragmática e da Linguística Histórica, bem como de uma proposta de Análise do Discurso realizada sob um viés diacrônico.

De acordo com J. Kabatek (2001, 2003, 2004), o reconhecimento de um gênero discursivo implica que se verifiquem algumas características fixas presentes na estruturação formal dos textos, de tal modo que a comunicação dos falantes se organize e fundamente segundo moldes tradicionais de realização discursiva. Torna-se necessário considerar, portanto, a existência de um conjunto de traços estilísticos e esquemas textuais convencionais, acordados entre os falantes, que constituem, ao fim e ao cabo, os gêneros discursivos. O reconhecimento, emprego e transmissão desses modelos discursivos ao

\footnotetext{
1 O presente trabalho está inserido nas pesquisas do GT "Tradições discursivas: constituição e mudança dos gêneros discursivos numa perspectiva diacrônica”, coordenado pela Profa. Dra. Maria Lúcia C. V. de O. Andrade, no âmbito do Projeto Caipira - grupo paulista de estudos históricos do português, coordenado pelo Prof. Dr. Ataliba Teixeira de Castilho.
} 
longo do tempo permitem, por conseguinte, a manutenção das características genéricas básicas, sem que se descartem as eventuais necessidades de adequação aos contextos de época.

Com efeito, todo texto consiste na materialização de um gênero discursivo e deve seguir as coerções por este determinadas, para que a comunicação possa ser estabelecida de maneira eficaz. Os gêneros textuais demandam o reconhecimento e a utilização de esquemas textuais no âmbito das superestruturas de organização lingüístico-discursivas e de conteúdos temáticos que são pertinentes à sua configuração. A esse conjunto de traços que são transmitidos pelas sucessivas gerações de indivíduos que falam e escrevem, definindo a unidade e a especificidade dos gêneros textuais, dá-se o nome de tradições discursivas.

Conforme ressalta V. Gomes (2005: 87-88), essas tradições não são fixas stricto sensu, mas podem mudar ao longo do tempo, sobretudo quando motivadas pelos fatores sócio-históricos, os quais estão presentes na base de toda e qualquer atividade comunicativa e interacional. Por outro lado, as tradições discursivas são constituídas em função da permanência de traços que garantem a continuidade de um gênero discursivo ao longo da sua transmissão, possibilitando o reconhecimento e a identificação das formas veiculadas por parte dos falantes de diferentes épocas. Dessa forma, a delimitação de um determinado gênero discursivo torna-se mais precisa mediante o conhecimento dos processos de sua formação histórica, isto é, de sua configuração a partir de certas tradições que o constituem ao longo do tempo e que possibilitam a comunicação eficiente entre os indivíduos. As pesquisas acerca das tradições discursivas revelam-se igualmente essenciais para os trabalhos de elaboração de corpora diacrônicos de análise lingüística e para a organização de tipologias textuais.

O estudo das tradições discursivas está intimamente ligado ao movimento histórico de mudança lingüística e possibilita, como observa Gomes (2005: 87), o estabelecimento de diversas relações entre os domínios textual (relativo ao uso) e lingüístico (relativo ao sistema). Desse modo, a leitura comparativa de documentos pertencentes a tempos distintos revela a ocorrência de mudanças não apenas no nível gramatical, mas também no plano discursivo, ou seja, na própria constituição do gênero textual, conforme demonstram diversas pesquisas recentemente desenvolvidas, sobretudo no âmbito dos estudos da Romanística alemã. Brigitte Schlieben-Lange (1983) cunhou o termo Pragmática Histórica, evidenciando a relação essencial entre o estudo pragmático e a diacronia lingüística, da mesma forma que R. Schmidt-Riese (2002) procura delimitar os procedimentos metodológicos de uma Análise do Discurso realizada segundo a perspectiva histórica, observando os textos sob um viés diacrônico.

Tomando por base a visão teórica de M. Foucault (1966, 1969, apud Kabatek: 2004), para o qual o discurso equivale às "condições do falar sobre entidades potencialmente, mas não necessariamente coincidentes com determinadas práticas sociais", assim como às condições e circunstâncias que subjazem às mesmas práticas, consideradas segundo os diversos setores da atividade social, Schmidt-Riese (2002: 15-17) propõe que sejam levadas em consideração, no estudo dos textos históricos, as realidades linguiísticas e não-lingüísticas. Ultrapassando os limites dos estudos filológicos, é preciso levar em consideração também a perspectiva sociológica, para a qual o falar é uma atividade social relacionada à representação da realidade. Assim sendo, considerando a documentação escrita preservada como discurso histórico, Schmidt-Riese (2002: 19-24) alerta para que não sejam relegadas a segundo plano as condições de produção relativas ao contexto de época ou mesmo a lembrança de que possivelmente grande parte da documentação 
existente à época tenha sido perdida, tal como aconteceram com os discursos orais, esses sim, irrecuperáveis em sua totalidade. Os textos conservados pela escrita, por outro lado, auxiliam na reconstrução do momento histórico e permitem recuperar as formas de pensar de um período a partir de sua produção textual. Tais aspectos apontam para significativas contribuições que a Análise do Discurso pode trazer às demais áreas das ciências humanas, a partir do instante em que se debruçar atentamente sobre os escritos de época.

W. Oesterreicher $(2001 \mathrm{a} ; 2002)$ introduz o conceito de espaço comunicativo, termo utilizado para designar o fato de que as tradições discursivas funcionam em virtude da determinação histórica de situações comunicativas. Assim, o discurso individual é guiado por modelos discursivos tradicionais, os quais, segundo o autor, "controlam os traços específicos de cada discurso no interior do contínuo concepcional entre imediatez e distância comunicativas". De acordo com Oesterreicher (1996, 2001a, 2002), é preciso observar, quanto à relação entre os aspectos histórico e semiótico, no que tange ao conceito de autonomização do texto, que certos tipos de discurso aparecem "sistematicamente no meio gráfico", o que pode tornar-se um problema no tratamento de textos antigos que foram preservados, pois nestes apenas conservam-se os discursos enunciados, tendo desaparecido as referências diretas às configurações discursivas específicas a eles relacionadas, às condições de produção do enunciado e às circunstâncias de comunicação. $\mathrm{O}$ autor sustenta que, muitas vezes, ocorrem "interpretações divergentes de um mesmo texto antigo" porque é provável que o discurso parta "de um conjunto gestual e simbólico que não tem reflexos nos textos conservados". Ao apresentar o conceito de recontextualização, Oesterreicher (2001a) mostra a possibilidade de recuperar as múltiplas modalidades semióticas do evento comunicativo original, cujas marcas desapareceram do texto conservado. Contudo, a recuperação do contexto original de produção de um texto, ao qual este é devolvido, nem sempre é algo possível e, nesses casos, o pesquisador tem que conviver com ambigüidades de interpretação e sentidos duvidosos que acabam sendo originados pela perda de referências importantes para a compreensão do texto antigo na sua totalidade.

Com relação à constituição histórica dos gêneros textuais, Kabatek (2003: 6-8) mostra que as tradições discursivas são transferíveis de uma língua para outra, no que decorre o princípio universal de existência de tais modelos. A interferência entre as línguas permite a troca de aspectos discursivos e culturais, levando a processos de inovação lingüística, na medida em que a adoção de novas tradições discursivas (interferência positiva) implica em novas criações lingüísticas. Kabatek se refere à possibilidade de haver uma interferência negativa entre as línguas, na qual não ocorre adoção, mas sim, ausência ou rechaço de elementos lingüísticos. Por outro lado, as tradições discursivas estão também relacionadas, segundo Kabatek (2003: 4-5), às questões de economia lingüística e de intertextualidade, pelo fato de ser "mais econômico repetir um esquema textual guardado na memória que criar um texto totalmente novo" e porque, em todo modelo textual que se repete, é estabelecida "uma relação entre o texto e outros textos já ditos ou escritos". Ressalte-se que as tradições discursivas, pertencentes ao âmbito da linguagem, apresentam as mesmas características que uma outra tradição cultural qualquer, configurando-se a partir da relação entre os sujeitos históricos e o mundo no qual eles se inserem e constroem. Notese também o fato, decorrente de fatores sócio-históricos, de que existem épocas da história que são mais conservadoras quanto à introdução de novas tradições discursivas, enquanto que outras épocas mostram-se bem mais inovadoras e revolucionárias com relação à adoção de um novo modelo textual. Da mesma forma, do ponto de vista social, verifica-se que a 
adoção de novas tradições discursivas ocorre, com maior freqüência, no âmbito das instituições que se configuram como centros de poder e transmitem as inovações, em detrimento das áreas sociais menos privilegiadas, freqüentemente colocadas como marginais e periféricas (cf. Kabatek: 2003, 10).

Oesterreicher (2001), visando situar as tradições discursivas na teoria lingüística, estabelece uma relação entre os conceitos de fala e escrita com os diferentes níveis da linguagem propostos por E. Coseriu (1988: 70). Inicialmente, no nível universal, os indivíduos seguem as exigências da imediatez ou da distância comunicativas entre os falantes, sendo as estratégias de comunicação determinadas por fatores cognitivos fundamentais - trata-se do falar entendido em seu sentido geral, como "atividade universal genericamente humana". No nível histórico, encontram-se as tradições discursivas - para Oesterreicher, o termo abarca os modelos tradicionais de realização dos gêneros literários e não literários, bem como dos tipos textuais, - e a atividade do falar de acordo com uma dada tradição histórica; o segundo aspecto diz respeito às línguas históricas particulares, que apresentam variedades faladas e escritas, segundo regras determinadas pela história particular de cada língua - trata-se da duplicação deste nível, a partir da inserção das tradições discursivas no seu domínio, conforme demonstrou Kabatek $(2001,2003,2004){ }^{2}$ Finalmente, no nível individual, a relação corresponde ao discurso enquanto atualização do falar por um indivíduo, concretizando o material da fala ou da escrita em uma determinada situação de produção - trata-se do ato discursivo individual, a atividade do falar propriamente dita.

O trabalho que ora se apresenta inscreve-se na agenda de critérios metodológicos proposta pelo texto de Kabatek (2003), na medida em que parte da delimitação de um universo discursivo fixado temporal e geograficamente, do recorte de um meio linguí́stico específico - o meio gráfico mediante o qual são transmitidos os textos jornalísticos impressos -, da observação da constituição de um gênero em momentos históricos diversos (verificação de conservações e mudanças a partir do estudo das tradições discursivas), relacionando sincronia e diacronia por meio da observação de permanências e descontinuidades em um determinado gênero textual.

\section{Estudo das cartas do redator do jornal $O$ Farol Paulistano, sob a perspectiva teórica das tradições discursivas}

\footnotetext{
2 A relação entre os conceitos de língua, texto e historicidade (cf. Kabatek: 2001, 2004) deve ser aqui mencionada. À historicidade da língua equivale a historicidade do próprio indivíduo como sujeito, este entendido como membro de uma comunidade histórica à qual se liga, sobretudo, em função de sua língua materna, por meio da qual são transmitidos valores, saberes e crenças. A língua tem, por sua vez, um caráter a-histórico, na medida em que não tem fim, "se cria e recria numa sucessão interminável de atos que não têm um princípio delimitável” (Kabatek: 2001, 103). As tradições discursivas, por outro lado, têm caráter histórico porque são "delimitáveis no eixo temporal" (Kabatek, op. cit.), como qualquer outra tradição cultural. A historicidade das tradições discursivas está relacionada aos textos, exemplares individuais concretos que remetem aos modelos tradicionais de concretização, anteriormente realizados.
} 
As cartas do redator do jornal $O$ Farol Paulistano, analisadas neste trabalho, podem ser consideradas textos iniciadores da tradição de um gênero discursivo específico - o editorial jornalístico. Partindo da observação de como esse gênero originalmente se constitui, ainda de maneira incipiente, no periódico em estudo, serão investigados alguns traços, nos planos discursivo e lingüístico, que permitam considerar os textos extraídos do referido jornal como precursores dos editoriais que são produzidos atualmente. Conforme afirma L. A. Marcuschi (2000: 104, apud Gomes: 2005, 89), ao discorrer a respeito da natureza dos gêneros textuais: "Todos os gêneros são históricos e têm origem em práticas sociais". Dessa forma, a análise das cartas do redator do jornal O Farol Paulistano está inserida em uma linha teórica que considera amplamente o contexto sócio-histórico da produção discursiva e as circunstâncias de composição textual. Tomando como base a perspectiva teórica das tradições discursivas, será estabelecida uma linha de continuidade entre os proto-editoriais jornalísticos de um periódico da primeira metade do século XIX e as características que definem o gênero discursivo editorial na atualidade, verificando de que forma o primeiro jornal impresso de São Paulo abriu caminho para as publicações posteriores, apresentando, no caso dos editoriais, certas marcas lingüísticas e discursivas que foram conservadas ao longo do tempo e que já eram visíveis nos primeiros textos publicados. Por outro lado, o exame dos traços que definem os editoriais na atualidade permite estabelecer um contraste com os textos inauguradores da tradição, presentes no primeiro periódico impresso, em função das significativas modificações que os jornais atuais apresentam com relação ao gênero textual em questão.

O jornal $O$ Farol Paulistano foi fundado e redigido pelo Dr. José da Costa Carvalho, o qual posteriormente intitulou-se, de acordo com N. Sodré (1999: 87), "barão, visconde e marquês de Monte Alegre", chegando a ser regente em 1831 e presidente da Província de São Paulo em 1842. O aparecimento tardio do primeiro jornal impresso da cidade de São Paulo ocorreu no dia 07 de fevereiro de 1827 e sua circulação foi inicialmente semanal, passando a ser bi-semanal somente a partir do mês de junho de 1827 . $O$ Farol foi publicado até o ano de 1831; no entanto, para o presente trabalho, serão levados em consideração apenas os periódicos do ano de 1827, na medida em que textos que efetivamente possam ser considerados precursores do editorial foram publicados, com alta frequiência, ao longo do primeiro ano de existência do jornal. Após esse período, ainda aparecem, vez por outra, nos números posteriores, textos que expressam nitidamente a posição do jornal a respeito de algum assunto do momento; contudo, na maior parte dos casos, tais textos vão sendo gradativamente substituídos pelos chamados "Artigos de Ofício" - cujas características diferem em grande medida dos textos selecionados para estudo, apresentando claramente a opinião de um autor identificado de maneira particularizada - ou por matérias extraídas de outros periódicos com posicionamentos políticos e ideológicos semelhantes. Dessa maneira, o recorte observacional do presente trabalho focaliza os textos opinativos do ano de estréia, 1827, nos quais as marcas lingüístico-discursivas que apontam para um nascimento do gênero editorial na imprensa paulistana estão presentes com maior intensidade. A leitura dos textos extraídos d'O Farol Paulistano permite notar uma tendência comum a grande parte dos periódicos brasileiros impressos na primeira metade do século XIX, no tocante à adesão de uma postura marcadamente política e engajada, de defesa de certos valores sociais e morais, os quais são expressos por meio de um tom panfletário, exaltado e inflamado, numa acirrada defesa da perspectiva ideológica assumida. Já em seu artigo de apresentação, na abertura do primeiro 
número, o jornal é definido como sendo de tendências liberais, assumindo abertamente uma posição política que permanecerá evidente até o seu último número.

$O$ texto de auto-apresentação d' $O$ Farol Paulistano define previamente a linha ideológica que o jornal seguirá ao longo das sucessivas edições, adiantando a posição política que será por ele defendida e explicitando o trabalho editorial e os objetivos que estarão por trás de cada publicação. Inserido no espaço que será ocupado, na maior parte das vezes, por editoriais incipientes, o texto de estréia (OFP 01, 1\%/02/1827) já apresenta alguns elementos linguiísticos e discursivos que aparecerão nas páginas de abertura posteriores. Em primeiro lugar, o tema da liberdade é enfatizado e euforizado como um desejo universal, pulsante nos indivíduos de todas as nacionalidades ("Todas as nações querem ser livres"). O autor reforça, desse modo, o principal valor defendido pelo jornal, colocando-o em evidente contraposição ao "despotismo", elemento tomado como alvo constante do ataque combativo dos liberais. O título do jornal é explicado mediante o desejo de iluminação do caminho a ser percorrido pelos membros da nação e, em particular, dos cidadãos paulistanos, os quais terão como guia a luz projetada em suas mentes pelo jornal, representado metaforicamente pela figura do farol.

$\mathrm{O}$ texto, avançando um pouco mais, assume um caráter metalingüístico ao definir a função a ser desempenhada, no âmbito de uma sociedade livre, pela imprensa, a qual é considerada "companheira e auxiliar da liberdade", apresentando, portanto, um relevante papel no contexto da época, quando o Brasil ainda era recém-independente de Portugal. Centrando suas considerações em São Paulo, cidade de cujos anseios e expectativas o jornal se propunha a ser porta-voz, o autor defende "o livre direito de publicar os pensamentos acerca de assuntos de interesse geral", explicitando o caráter público dos textos jornalísticos, apoiando e legitimando sua proposta de trabalho nos direitos garantidos pela Constituição, expressando por fim o "desejo de ser útil a todo o Brasil". Afirma defender a liberdade no momento atual com vistas à felicidade das futuras gerações e convoca a adesão dos cidadãos paulistas ao novo empreendimento editorial, convidando-os a participar e a contribuir com informações, notícias e opiniões.

Após haver captado a benevolência dos leitores para si e para seu discurso, bem como mostrado as principais linhas que definem a proposta do jornal, o enunciador parte para a apresentação geral da estrutura do periódico, expondo sua divisão básica, descrevendo as principais seções e discorrendo sobre o conteúdo temático associado a cada uma delas. $\mathrm{O}$ gérmen do simulacro de imparcialidade que está efetivamente presente nos jornais contemporâneos pode ser verificado já nestes primeiros textos, ainda que uma forte contradição permeie explicitamente todos os discursos defensores da objetividade nos periódicos do século XIX: ao mesmo tempo em que o enunciador se compromete a adotar uma postura distanciada e objetiva em relação aos fatos, ele imprime, logo em seguida, marcas claras de subjetividade e filiação ideológica. É o que se observa já neste primeiro texto de abertura, no qual afirma-se que serão feitas "reflexões imparciais", mas, a o mesmo tempo, "dando com larga mão os merecidos elogios a que os merecem" e "francamente garantindo que diremos nossa opinião a cerca d'aquelles que nos parecem menos bons". Do ponto de vista lingüístico, nota-se, neste texto e nas cartas do redator tomadas para análise, o uso predominante da primeira pessoa do plural, característica que não foi conservada pelos textos de opinião do presente, nos quais predomina a terceira pessoa do singular, utilizada com o objetivo de criar um efeito maior de objetividade, ainda que este seja apenas simulado, e de reforçar as impressões de imparcialidade e distanciamento, 
mascarando as tomadas de posição e as linhas ideológicas assumidas pelos textos jornalísticos.

A epígrafe d'O Farol (La libertè est une enclume qui userá tous les marteaux), escrita em francês, além de sinalizar a recorrência das citações de textos escritos em línguas estrangeiras que caracteriza os jornais do período, sintetiza a perspectiva política e ideológica assumida pelo jornal ao longo de todos os seus números, norteando o olhar do leitor e antecipando o ponto de vista defendido à exaustão pelos textos publicados. Trata-se, como relembra o enunciador que substitui o "Primeiro Redactor do Farol Paulistano", o qual "d'esta cidade partio para a Corte do Rio de Janeiro no dia nove do corrente Abril [1827]", de uma frase de abertura que confere unidade ao conjunto de textos do periódico, garantindo a continuidade coerente do trabalho editorial defendido e reafirmando a adesão aos valores e ideais que o primeiro número do jornal já apresentara com caráter fortemente programático. Em função da primeira grande modificação sofrida pelo jornal, a mudança de redator, o novo autor da coluna e coordenador da publicação reforça a proposta do jornal, recordando em português o lema d' $O$ Farol, na mesma carta do redator acima referida: “[...] esperamos producções interessantes para a nossa folha; é dos nossos correspondentes e de alguns outros socorros extranhos que ha de vir luz ao Farol. De resto, pode chover sobre nós e sobre a nossa folha toda a sorte de improperios, de injurias e de ameaças: $a$ liberdade é uma bigorna, que gastará todos os martelos" (OFP 12, 25/04/1827).

Os editoriais jornalísticos do século XIX, como observa Gomes (2005: 90), em seu estudo de aplicação da teoria das tradições discursivas aos periódicos de Pernambuco, tinham um caráter marcadamente artesanal, com predomínio de um estilo muito mais doutrinário, propagandístico e panfletário do que propriamente factual, descritivo ou informativo. Os discursos dos editoriais d'O Farol Paulistano apresentam um tom veemente e inflamado, tendendo muito mais para o excesso do que para o equilíbrio, o que evidencia de modo muito mais claro a defesa de um ponto de vista específico, a escolha preferencial de uma perspectiva ideológica em detrimento de outra, a tomada de um partido definido e estabelecido, a adesão a uma causa política determinada e a exaltação de valores e ideais próprios. Segundo C. A. Rabaça \& G. Barbosa (1978), o editorial, ao expressar o ponto de vista de um jornal acerca dos fatos, acontecimentos e assuntos em voga no momento, assume inevitavelmente o caráter de um texto de opinião. Tendo em vista a formação da opinião pública ao procurar garantir a adesão dos leitores a uma perspectiva explicitada em maior ou menor grau pelo texto, os editoriais procuram fazer com que o público leitor entre em conjunção com os valores e ideais defendidos pela instituição jornalística. Conforme assinala N. Discini (2004: 212-213), o discurso jornalístico visa criar três efeitos centrais de sentido, mediante a realidade construída pelo discurso (efeito de realidade), por meio da ilusão ou do simulacro de objetividade que é construído pelo próprio sujeito do jornal (efeito de objetividade) ${ }^{3}$ e, finalmente, por meio do "simulacro de um dizer verdadeiro" que legitima tanto a enunciação quanto o enunciado, de tal forma a cumprir o preceito retórico aristotélico segundo o qual a aparência do verdadeiro é o que realmente importa, relegando a discutível verdade absoluta a um segundo plano (efeito de verdade). $\mathrm{O}$ estudo de Discini sobre os editoriais da atualidade instaura uma diferença fundamental em relação aos editoriais incipientes do passado, na medida em que os jornais contemporâneos primam pela implicatura do narrador, que se oculta nos discursos

3 Segundo Discini (2004: 213): “A enunciação, sempre pressuposta, faz crer no próprio alheamento para fazer-crer na própria imparcialidade". 
jornalísticos atuais. Os exemplos transcritos a seguir, extraídos d' $O$ Farol Paulistano apontam para uma descontinuidade presente na história do gênero editorial no Português Brasileiro, na medida em que os periódicos do século XIX utilizam predominantemente a voz coletiva da primeira pessoa do plural na construção do texto - ora exclusiva, ora inclusiva -, o que reduz em grande parte os efeitos de objetividade e imparcialidade:

(a) Muito apreciamos a delicada ironia com que o nosso correspondente ridiculariza os argumentos [...] (OFP 9, 04/04/1827)

(b) [...] a quem a educação entre nós, pela maior parte, priva de poderem examinar questões de direito público. (OFP 9, 04/04/1827)

(c) $[\ldots]$ diremos quatro palavras chãs, e sem rebuço. (OFP 9, 04/04/1827)

(d) Felizmente os nossos religiosos [...] (OFP 9, 04/04/1827)

(e) É esta a occazião, que julgamos opportuna para dizer alguma couza acerca de sua administração [...] (OFP 10, 11/04/1827)

(f) $[\ldots]$ e sem perigo de parecermos lizonjeiros, com mão imparcial dar lhe os elogios de que o julgamos merecedor [...] (OFP 10, 11/04/1827)

(g) [...] mas bastante, bastante receamos menos feliz sorte. (OFP 10, 11/04/1827)

(h) $[\ldots]$ apesar de reconhecermos a nossa insufficiencia. (OFP 12, 25/04/1827)

(i) [...] marchando impavidos, como convem a quem não se sente pungido pelos remorosos, seguiremos em tudo o plano traçado pelo nosso Antecessor. (OFP 12, 25/04/1827)

(j) [...] asseveramos, que não é dos nossos conhecimentos (aliás nenhuns) que esperamos producções interessantes para a nossa folha; é dos nossos Correspondentes e de alguns outros socorros extranhos que ha de vir luz ao Farol. (OFP 12, 25/04/1827)

(k) $[\ldots]$ e eis o que nos desanima [...] (OFP 13, 02/05/1827)

(l) Julgamos por tanto de nosso dever reprodusir os argumentos que se offerecem a favor da votação per capita. (OFP 13, 02/05/1827)

(m) dir nos hão [...] (OFP 13, 02/05/1827)

(n) Como Escriptor publico, a imparcialidade será o nosso Norte, e é por isso que prevenimos aos nossos leitores de que no caso de não apparecer em a nossa folha sobre esta materia correspondencia alguma em contrario, será isto uma prova de que os nossos illustres patricios são unanimes em adoptar a nossa opinião. (OFP 13, 02/05/1827)

(o) O nosso estimavel patricio [...] (OFP 39, 22/08/1827)

(p) Mas desejando rivalizar em patriotismo com o nosso benemerito antecessor julgamos que mais conviria continuar com a publicação da folha [...] (OFP 39, 22/08/1827) 
(q) os primeiros em fim que desenganamos a alguns adversarios nossos [...] (OFP 44, 07/09/1827)

(r) [...] em fim somos tudo pois que somos livres. (OFP 44, 07/09/1827)

(s) Passemos á fradesca exclamação [...] (OFP 53, 10/10/1827)

(t) Muito dezejavamos poder dar aos nossos Leitores [...] (OFP 71, 12/12/1827)

Em alguns casos, até mesmo a primeira pessoa do singular é utilizada, elevando ao grau máximo a presença de subjetividade e revelando o comprometimento do sujeito enunciador. Entretanto, não há, nesses textos, assinatura do autor, recaindo a marca de autoria sobre a voz do jornal ou, quando muito, do redator, o qual, algumas raras vezes, assina a seção. Observem-se os exemplos:

(a) [...] tem abismado em um montão de ruinas a patria de seus paes e de seus irmãos (não digo a sua porque elles a não tem) [...] (OFP 9, 04/04/1827)

(b) Fallo agora das monacaes, porque se trata de propriedade [...] (OFP 9, 04/04/1827)

O uso dos pronomes de primeira pessoa do plural nos proto-editoriais jornalísticos (e por vezes da primeira pessoa do singular), bem como dos verbos conjugados na primeira pessoa, aponta, portanto, para uma ruptura nos moldes tradicionais de caracterização e apresentação do sujeito enunciador nesse gênero discursivo. As marcas de pessoa são trocadas no percurso histórico do gênero editorial para aumentar a impressão de ausência do sujeito enunciador e de não comprometimento ideológico do jornal. Observem-se, agora, exemplos colhidos em jornais do presente, extraídos do texto de Discini, no qual a autora trabalha com o editorial da Folha de S. Paulo do dia 31/10/2003:

(a) Esta Folha já se declarou favorável à liberação da soja transgênica.

(b) Esta Folha considera que o consumidor deve ser informado.

Não obstante as mudanças operadas no modo de dizer do sujeito enunciador, depreensível da materialidade do texto, é conservada, nos editoriais produzidos na atualidade, a expressão de um ponto de vista assumido pelo jornal frente à realidade construída discursivamente, permanecendo a busca de adesão do público leitor aos valores e à tese defendidos pela instituição jornalística, por meio da utilização de estratégias argumentativas de persuasão e convencimento. Nota-se, ainda, a manutenção de um tom de certeza nas afirmações feitas, apesar do abrandamento do tom com que a veiculação de uma 
dada visão de mundo é feita, na medida em que o tom exaltado foi substituído, ao longo do tempo, por um tom mais sereno e equilibrado, típico de um sujeito que objetiva construir um discurso dotado de maior leveza, tal como observa Santana (2003: 113) em sua caracterização do estilo do editorial jornalístico contemporâneo.

Note-se a contrariedade presente nos discursos que afirmam a imparcialidade e objetivam a impessoalidade, mas que, em seguida, deixam transparecer claramente marcas subjetivas intensas, por vezes assumindo a voz de um enunciador coletivo e revelando a relação entre enunciador e enunciatário:

(a) [...] e sem perigo de parecermos lizonjeiros, com mão imparcial dar lhe os elogios de que o julgamos merecedor [...] (OFP 10, 11/04/1827)

(b) Aceite o $\operatorname{Exm}^{\circ}$. Visconde de Congonhas este publico tributo de gratidão de uma penna, que nunca lizonjeou, e que mesmo algumas vezes censurou alguns actos que lhe não pareceram bons, com aquelle mesmo espirito de rectidão, e imparcialidade, que hoje a determina. (OFP 10, $11 / 04 / 1827)$

(c) Como Escriptor publico, a imparcialidade será o nosso Norte, e é por isso que prevenimos aos nossos leitores de que no caso de não apparecer em a nossa folha sobre esta materia correspondencia alguma em contrario, será isto uma prova de que os nossos illustres patricios são unanimes em adoptar a nossa opinião. (OFP 13, 02/05/1827)

Além do uso predominante da $1^{\mathrm{a}}$ pessoa do plural, o qual promove a impressão de uma forte e acentuada marca de subjetividade ao discurso e rivaliza com a pretensa proposta de um olhar imparcial sobre os fatos comentados, as cartas do redator d' $O$ Farol Paulistano apresentam outros traços que as vinculam à história do gênero discurso editorial - ora por se aproximarem da configuração dos textos produzidos na atualidade em função da presença de elementos que foram preservados e perpetuados ao longo do tempo, ora por expressarem um grau de afastamento em relação a certos traços inovadores que foram sendo incorporados à constituição do gênero discursivo editorial no decorrer de sua história. Dessa forma, a incidência de adjetivações, traço característico de todo texto de opinião, representa um daqueles elementos que foram preservados no curso da história dos editoriais jornalísticos, ainda que, nas primeiras cartas do redator do periódico paulistano sob exame, fosse também recorrente a utilização de uma construção sintática de anteposição dos adjetivos ao núcleo de um determinado sintagma nominal. As ocorrências listadas a seguir comprovam uma recorrente utilização de adjetivos antepostos ao nome, nos primitivos editoriais d'O Farol, ao lado do uso também freqüente de adjetivos pospostos ao nome, o que assinala uma tentativa intencional de reforço do caráter tipicamente opinativo dos textos impressos que veiculam a voz oficial do periódico em que estão inseridos:

1) [...] a delicada ironia [...] (OFP 9, 04/04/1827)

2) [...] fazendo os aparecer em um escolhido tribunal de senhoras [...] (OFP 9, 04/04/1827)

3) $[\ldots]$ pois só Jesuitas ou pessoas infectadas de suas maximas, podem ensinar tal doutrina [...] (OFP 9, 04/04/1827) 
4) [...] a velha Jezuitica (OFP 9, 04/04/1827)

5) [...] diremos quatro palavras chãs [...] (OFP 9, 04/04/1827)

6) $[\ldots]$ na sua primitiva constituição $[\ldots]$ (OFP 10, 11/04/1827)

7) [...] com mão imparcial [...] (OFP 10, 11/04/1827)

8) $[\ldots]$ o imprudente ministerio $[\ldots]$ (OFP 10, 11/04/1827)

9) Muito lhe deve a Provincia de S. Paulo, pois ainda, que não fosse traçado um plano geral, e em grande de melhoramento, contudo, os teve parciaes, e desligados, mas vantajozos, e alguns muito uteis. (OFP 10, 11/04/1827)

10) $[\ldots]$ este digno varão $[\ldots]$ (OFP 10, 11/04/1827)

11) $[\ldots]$ a melindrosa tarefa $[\ldots]($ OFP $12,25 / 04 / 1827)$

12) A quadra é assaz mingoada [...] (OFP 12, 25/04/1827)

13) [...] um trabalho para nós mui rude $[\ldots]$ (OFP 12, 25/04/1827)

14) [...] nossas outras laboriosas ocupações [...] (OFP 12, 25/04/1827)

15) A grata sensação que experimentamos [...] (OFP 13, 02/05/1827)

16) [...] tão gratas recordações [...] (OFP 13, 02/05/1827)

17) $[\ldots]$ desastrada questão [...] (OFP 13, 02/05/1827)

18) [...] mas acontece que as razões a favor da votação per capita são tam claras, tam terminantes e tam irreplicaveis, que estamos convencidos; (OFP 13, 02/05/1827)

19) Que longo e insupportavel proceso! (OFP 13, 02/05/1827)

20) $[\ldots]$ os nossos illustres patricios [...] (OFP 13, 02/05/1827)

21) O Dia 3 de Maio, já célebre nos fastos Brazileiros [...] (OFP 14, 09/05/1827)

22) [...] a rica terra de Sancta Cruz [...] (OFP 14, 09/05/1827)

23) $[\ldots]$ neste paiz abençoado $[\ldots]$ (OFP 14, 09/05/1827)

24) [...] os Brazileiros admirados e gostosos [...] (OFP 14, 09/05/1827)

25) [...] um pôvo nascente e já grande. (OFP 14, 09/05/1827)

26) $[\ldots]$ d'este acto majestoso [...] (OFP 14, 09/05/1827)

27) [...] seos augustos trabalhos [...] (OFP 14, 09/05/1827)

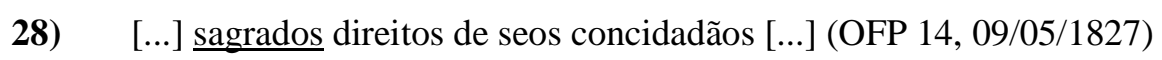

29) $[\ldots]$ alto grao de esplendor [...] (OFP 16, 23/05/1827)

30) $[\ldots]$ quadro magnifico $[\ldots]$ (OFP 16, 23/05/1827)

31) Despotas insensatos, sempre temerosos e sempre maquinadores [...] (OFP 16, 23/05/1827)

32) $[\ldots]$ risos fingidos $[\ldots]$ (OFP 16, 23/05/1827)

33) $[\ldots]$ aquelle dia memoravel [...] (OFP 16, 23/05/1827)

34) O nosso estimavel patricio [...] (OFP 39, 22/08/1827)

35) [...] tão laboriosa tarefa [...] (OFP 39, 22/08/1827)

36) $[\ldots]$ o nosso benemerito antecessor [...] (OFP 39, 22/08/1827) 
37) O brado electrico [...] (OFP 44, 07/09/1827)

38) [...] verdadeiros filhos do Brazil [...] (OFP 44, 07/09/1827)

39) [...] palavras magicas [...] (OFP 44, 07/09/1827)

40) O Divino Mestre dos Apostolos [...] (OFP 50, 29/09/1827)

41) [...] tão delicados ouvidos [...] (OFP 50, 29/09/1827)

42) [...] Priamo, velho monarcha asiático [...] (OFP 50, 29/09/1827)

43) O nobre Castelhano [...] (OFP 50, 29/09/1827)

44) [...] a celeberrima Gazeta do Brazil [...] (OFP 53, 10/10/1827)

45) [...] tão fraco apoio [...] (OFP 53, 10/10/1827)

46) O Sr. Ferreira França é muito conhecido em todo o Brazil; suas maneiras singellas, suas opinioens francas são continuadas e vivissimas reprehensoens a todas essas gralhas empavonadas, que brilhão com emprestados externos atavîos, com os quaes mal se caza o oiro puro das virtudes publicas, e particulares. (OFP 53, 10/10/1827)

47) [...] fradesca exclamação [...] (OFP 53, 10/10/1827)

48) [...] da sua ditosa Acclamação. (OFP 54, 13/10/1827)

49) Este dia glorioso [...] (OFP 54, 13/10/1827)

50) [...] da mais grata recordação [...] (OFP 54, 13/10/1827)

51) [...] sua pátria natal ou adoptiva. (OFP 54, 13/10/1827)

52) [...] incomparaveis beneficios e vantagens [...] (OFP 54, 13/10/1827)

53) [...] na mais romóta posteridade [...] (OFP 54, 13/10/1827)

54) $[\ldots]$ as Sublimes e Insignes virtudes do PRIMEIRO IMPERADOR do Brazil, que $O$ tem já collocado em o pequeno número dos vrdadeiros heróes [...] (OFP 54, 13/10/1827)

55) $[\ldots]$ cuidadosamente tomamos os precisos apontamentos [...] (OFP 71, 12/12/1827)

56) [...] ainda que mais robustos fossem nossos hombros, e iguaes a tão pezada tarefa [...] (OFP 71, 12/12/1827)

57) [...] Estamos igualmente certissimos da generosa e patriotica cooperação dos muito respeitaveis Religiosos de S. Francisco d'esta Cidade [...] (OFP 72, 15/12/1827)

Verifica-se, na série de exemplos listados acima, uma freqüente utilização de termos e expressões adjetivais, com o intuito de marcar claramente a opinião do redator - e, portanto, a visão oficial do periódico - sobre os fatos comentados. Em muitos casos, inúmeros adjetivos são empregados em um único período (vejam-se, por exemplo, os de número $18,46,54,56$ ), alguns no grau superlativo - a reforçar o tom inflamado e veemente dos incisivos comentários -, outros resultando numa certa redundância que apenas contribui para o efeito reforçado da carga de veemência. A utilização de adjetivos antepostos aos substantivos é igualmente notável, mantendo-se o tom de engajamento e assinalando uma forte tomada de posição - o que permite afirmar que o recurso da adjetivação contribui, por sua vez, com o apagamento das possíveis intenções de neutralidade, revelando, uma vez 
mais, provas irrefutáveis da forte presença de subjetividade no discurso. As opiniões do sujeito enunciador são expressas na total ausência de imparcialidade, mediante o uso de adjetivos que trazem consigo, para o discurso, uma elevada carga semântica de subjetividade. Em comparação com os editoriais jornalísticos atuais, as antigas cartas do redator empregam, com muito mais freqüência, adjetivos que expressam, de modo evidente, os incisivos pensamentos e opiniões - por vezes carregadas de ironia - do sujeito enunciador. Conforme assinala L. Mosca (1990), em estudo acerca da subjetividade nos editoriais da atualidade, a adjetivação é um dos principais fatores que evidenciam o posicionamento de um jornal, "porta-voz da coletividade", diante dos fatos; no entanto, a utilização de adjetivos, nos editoriais contemporâneos, é feita de maneira criteriosa e acurada, evitando "quebrar o efeito global de objetividade" que se almeja para esse gênero de discurso. Este é, portanto, mais um traço de descontinuidade no percurso histórico do gênero em questão, apontando para o abrandamento de tom pelo qual o texto dos editoriais foi passando no decorrer de sua história. Discini (2004: 216), em seu artigo acerca dos editoriais contemporâneos, afirma que um dos recursos gramaticais utilizados para construir estratégias discursivas - no caso dos modernos editoriais, uma das principais estratégias é o simulacro do distanciamento imparcial - consiste justamente no "emprego de adjetivos com baixa carga semântica de subjetividade" (grifo nosso), apresentando, como exemplos, as seguintes ocorrências:

(a) O trabalho resgata vínculos históricos do PT com os ambientalistas. (FSP, 31/10/2003)

(b) Fica a sensação de que o CNBS (Conselho Nacional de Biossegurança) apenas dá uma expressão administrativa à polêmica dos OGMS (organismos geneticamente modificados). (FSP, 31/10/2003)

Outro elemento, presente nas cartas do redator d'O Farol, consiste na utilização de perguntas retóricas, feitas de forma veemente pelo enunciador, visando trazer o leitor para próximo de si e das opiniões defendidas pelo periódico - em relação às quais o redator deseja obter a máxima adesão e aceitação por parte do público. A resposta desejável, para tais perguntas, é a própria tomada de posição favorável à ideologia defendida pelo periódico. Tal estratégia de convencimento, ao mesmo tempo que evidencia a relação entre o enunciador e sua alteridade, conduz o raciocínio em direção a uma conclusão com pretensões de neutralidade - a qual, ao término da estratégica argumentação, assume um caráter de verdade lógica e universal. Observem-se as seguintes ocorrências de perguntas retóricas e perceba-se a contundência com que as caracteriza, numa relação que visa à total adesão do público leitor ao feixe de idéias e valores defendidos pelo jornal:

(a) Estimaes a Socrates, não é assim? Pode ser despresivel o nome de Barneveldt? Quaes quer que sejão os vossos prejuizos, Malesherbes não vôs imprime um certo respeito? Mas se Socrates, Barneveldt, e Malesherbes vivêssem hoje, quantos nóvos perseguidores não terião entre esses mesmos que mostrão admiral-os! (OFP 50, 29/09/1827) 
(b) Em que pois se tirão aqui os meios aos govêrno? De que modo se derriba o throno? Como se desacredita o governo? Como se sacrifica a honra e brio da Nação Brazileira? Se o throno, o brio e honra da Nação Brazileira dependessem de tão fraco apoio, mal de nós e mal do throno [...] (OFP 53, 10/10/1827)

(c) Passemos á fradesca exclamação respeitai a religião de nossos páes. Em que se ataca a Religião? É atacar a Religião propôr que seja casado o Clero? Senhores entendamos-nos: não se confunda a Religião com o que não é. (OFP 53, 10/10/1827)

A freqüente inserção de citações, grande parte em línguas estrangeiras, ao lado do emprego de perguntas retóricas, revelam o perfil de um protagonista culto que se dirige a um público ideal ilustrado o suficiente para reconhecer as eruditas alusões. Nas referências a Sócrates, Barneveldt, Malesherbes, mencionadas acima, bem como na citação das palavras do "Divino Mestre dos Apostolos", ou nas menções a "Priamo, velho monarcha asiatico", "a propria mensageira de Jupiter, Iris", "O nobre Castelhano, que, por ordem de Filipe $2^{\circ}$, estrangulou D. Carlos", pode ser notado o grau ideal de conhecimento partilhado entre o redator do jornal e o público leitor d'O Farol Paulistano. Da mesma forma, a mítica comparação estabelecida com a figura de D. Pedro I:

(a) [...] temos mais que tudo o IMMORTAL PEDRO PRIMEIRO que não hade querer, como o Saturno da Fabula, devorar sua propria filha. Elle a manterá, e o Brazil será Constitucional e livre. Já não pode retrogradar. (OFP 50, 29/09/1827)

Por fim, ao lado dos aspectos lingüístico-discursivos enumerados ao longo desta segunda seção, característicos dos proto-editoriais do século XIX, os textos de abertura do primeiro periódico paulistano impresso trazem consigo o gérmen dos editoriais jornalísticos desenvolvidos pela posteridade, na medida em que fazem transparecer a opinião oficial do jornal e apresentam a posição ideológica assumida e defendida pela publicação - não obstante o emprego do tom incisivo e veemente da inexperiência que ainda não aprendeu a simular a imparcialidade de maneira eficaz. Desse modo, o sujeito enunciador engajado não consegue ocultar-se totalmente, e evidências de sua presença podem ser depreendidas ao longo de toda a materialidade discursiva, permitindo a identificação de um ferrenho e autêntico porta-voz do liberalismo, no momento inicial de formação da imprensa paulistana.

\section{Conclusões}

$\mathrm{Na}$ perspectiva teórica das tradições discursivas, a permanência de traços lingüísticos e discursivos assegura a continuidade de um gênero textual ao longo de sua transmissão no eixo temporal, permitindo o reconhecimento e a identificação das formas discursivas veiculadas pelos indivíduos de diferentes épocas. É válido ressaltar que descontinuidades e rupturas ocorrem, sobretudo, em razão da influência de fatores sócio- 
históricos que condicionam, com o passar do tempo, modificações na configuração dos gêneros discursivos.

Com base na leitura e seleção de números do jornal $O$ Farol Paulistano, pode-se afirmar que as cartas do redator são os textos que mais se aproximam da configuração dos modernos editoriais jornalísticos, em relação aos quais apresentam, por um lado, traços caracterizadores semelhantes e, por outro, traços configuradores que apontam para a ocorrência de transformações, descontinuidades e rupturas ao longo do percurso histórico. Dessa forma, não obstante as mudanças verificadas nos planos lingüístico e discursivo, as antigas cartas do redator podem ser consideradas as precursoras dos editoriais da atualidade, na medida em que a permanência de um conjunto de traços, pelos quais os periódicos posteriores demonstraram completa adesão, permite constatar a continuidade do gênero. Tais elementos estão presentes, sobretudo, na veiculação da voz oficial do jornal, de seu posicionamento frente aos fatos contemporâneos e no caráter de opinião com que tais temas são abordados. As diferenças entre os textos do passado e os herdeiros atuais da tradição podem ser verificadas no processo de abrandamento do tom com que as opiniões do jornal são propagadas, ao lado de uma crescente simulação de neutralidade por parte do sujeito enunciador que expressa seus comentários. Assim, as marcas lingüísticas que contribuíam com o afastamento do ideal de imparcialidade foram sendo substituídas por outros traços - muitas vezes seus respectivos opostos -, na tentativa de ocultar, sob o tênue véu do comprometimento imparcial e objetivo com a verdade dos fatos, as pistas que possivelmente poderiam conduzir à relatividade de opiniões do sujeito enunciador e aos interesses particulares do jornal.

No curso desse processo de mascaramento das formações ideológicas, traços como o uso predominante da $1^{a}$ pessoa do plural, o emprego de adjetivos com elevada carga semântica - antepostos ou pospostos ao nome -, a ênfase nas repetições redundantes e no detalhamento informativo e descritivo, foram sendo gradativamente substituídos pelo uso predominante da $3^{\mathrm{a}}$ pessoa do singular, por uma preferência pelo emprego de adjetivos com baixa carga semântica - geralmente pospostos ao nome -, por uma linguagem mais transparente em busca de objetividade. Manteve-se, no entanto, o perfil de um redator que demonstra-se conhecedor da realidade e apto a emitir julgamentos e críticas sobre os fatos considerados relevantes. Da mesma forma, o perfil ideal do público dos editoriais jornalísticos permanece elitizado e geralmente identificado com o leitor escolarizado que almeja ter suas opiniões moldadas pela visão oficial de um órgão de imprensa e está apto a estabelecer analogias, reconhecer referências e anáforas, compreender estruturas sintáticas subordinadas.

A manutenção de traços lingüístico-discursivos, bem como as alterações e tentativas de simulação detectadas na configuração textual dos editoriais contemporâneos, à luz da análise detalhada das cartas do redator do jornal $O$ Farol Paulistano, permitem confirmar a existência de modelos discursivos gerais, temporalmente delimitáveis, que guiam o discurso individual e as configurações textuais - esquemas de características textuais básicas que se perpetuam ao longo do tempo e vêm sendo chamados, pelas pesquisas mais recentes, de tradições discursivas.

\section{Referências Bibliográficas}


DISCINI, Norma. O sujeito no jornal. In: Gragoatá. Niterói: EdUFF, $1^{\circ}$ semestre de 2004. no 16 , p. 209-227.

GOMES, Valéria Severina. História do editorial jornalístico em Pernambuco: o que mudou e o que permaneceu no curso desta tradição discursiva?. In: PESSOA, Marlos de Barros (Org.). Língua, textos e história: Manuscritos e impressos na história do português brasileiro. Recife: Programa de Pós-Graduação da UFPE, 2005. p. 87-107.

KABATEK, Johannes. Cómo investigar las tradiciones discursivas medievales? El ejemplo de los textos jurídicos castellanos. In: Daniel Jacob/ Johannes Kabatek (eds.). Lengua medieval y tradiciones discursivas en la Península Ibérica. Frankfurt am Main: Vervuert/Madrid: Iberoamericana, 2001. p. 97-132.

. Tradiciones discursivas y cambio lingüístico. Seminario de historia de la lengua española El cambio lingüístico en la historia española: nuevas perspectivas. Soria, del 7 al 11 de Julio de 2003.

. Sobre a historicidade de textos. Versão modificada de um capítulo do livro "Die bolognesische Renaissance" (2004), a ser publicado brevemente em Tübingen (Alemanha).Tradução para o português de José da Silva Simões. Inédito.

MOSCA, Lineide do Lago Salvador. Subjetividade no editorial: uma análise retóricoargumentativa da adjetivação. Tese de doutorado apresentada à FFLCH-USP. São Paulo: 1990.

OESTERREICHER, Wulf. Lo hablado en lo escrito. Reflexiones metodológicas y aproximación a una tipología. In: T. Kotschi/ W. Oesterreicher/ K. Zimmermann (eds.). El Español hablado y la cultura oral en España y Hispanoamérica. Frankfurt am Main: Vervuert/ Madrid: Hiberoamericana, 1996. p. 317-340.

. La "recontextualización" de los géneros medievales como tarea hermenéutica. In: Daniel Jacob/ Johannes Kabatek (eds.). Lengua medieval y tradiciones discursivas en la Península Ibérica. Frankfurt am Main: Vervuert/ Madrid: Iberoamericana, 2001. p. 199-231.

. Autonomización del texto y recontextualización. Dos problemas fundamentales en las ciencias del texto. In: Eduardo Hopkins Rodríguez (Editor). Homenaje Luis Jaime Cisneros. Lima: Pontificia Universidad Católica del Perú, 2002. vol. I. pp. 343-387.

RABAÇA, Carlos A.; Barbosa, Gustavo. Dicionário de comunicação. Rio de Janeiro: Codecri, 1978.

SCHMIDT-RIESE, Roland. Glosando las confesiones de los hermanos Ávila. Discurso e identidad en la Nueva España a finales del siglo XVI. In: Lexis, vol. XXVI (1): 3-78, 2002.

SANTANA, Denise Maria Rodrigues de. Substantivo e formalismo vocabular no gênero "editorial”. In: PAULIUKONIS, Maria Aparecida Lino e GAVAZZI, Sigrid (orgs.). Texto e discurso: mídia, literatura e ensino. Rio de Janeiro: Lucerna, 2003. p. 110-119.

SODRÉ, Nelson Werneck. História da imprensa no Brasil. 4.ed. Rio de Janeiro: Mauad, 1999. 


\begin{abstract}
Among the questions that are nowadays at the foreground of the Brazilian debate concerning Portuguese teaching, special attention is given to the several discourse genres and the way they ought to be worked out at school, under such perspective. Alongside the studies on discourse genres, another very recent approach in the field of linguistic studies in Brazil, has come to contribute to the comprehension of the subject, placing itself around the so called discourse traditions, a topic of studies of actual researches carried out by German linguists. The aim of this paper, supported by the concept of discourse genres, is to reestablish the historical of the constitution of the editorial. As study corpus was taken a XIX century journal named $\mathrm{O}$ Farol Paulistano, the first impressed newspaper in the city of Sao Paulo.
\end{abstract}

Key-words: diachronic discourse analysis; discourse traditions; discourse genres; editorial; Brazilian journals of XIX century; O Farol Paulistano. 